\title{
Preterm Birth a Risk Factor for Postpartum Depression in Pakistani Women
}

\author{
Salima Sulaiman Gulamani ${ }^{1}$, Shahirose Sadrudin Premji ${ }^{2}$, Zeenatkhanu Kanji ${ }^{1}$, \\ Syed Iqbal Azam ${ }^{3}$ \\ ${ }^{1}$ School of Nursing and Midwifery, Aga Khan University, Karachi, Pakistan \\ ${ }^{2}$ Faculty of Nursing, Department of Community Health Sciences, University of Calgary, Alberta, Canada \\ ${ }^{3}$ Community Health Sciences Department, Aga Khan University, Karachi, Pakistan \\ Email: salima.sulaiman@aku.edu
}

Received August $16^{\text {th }}, 2013$; revised September $17^{\text {th }}, 2013$; accepted September $25^{\text {th }}, 2013$

Copyright (C) 2013 Salima Sulaiman Gulamani et al. This is an open access article distributed under the Creative Commons Attribution License, which permits unrestricted use, distribution, and reproduction in any medium, provided the original work is properly cited.

\begin{abstract}
A Pakistani cohort of 170 mothers of full-term infants and 34 mothers of preterm infants were screened at 6 weeks after delivery to compare the rate of PPD, and examine the contribution of parenting stress and mother-infant interaction to PPD among mothers of preterm infants. Mothers completed the Edinburgh postnatal depression scale, and a general questionnaire. Mothers of preterm infants also completed the parental stress scale and parental bonding questionnaire. The rate of PPD was significantly higher with the adjusted odds increasing by 2.68 (95\% Confidence Interval $1.16-6.17, p=.015)$ in mothers of preterm infants. Significantly more depressed mothers of preterm infants did not receive some level of support from their husbands $(p=.014)$, and had some level of difficulty feeding $(p=.03)$ or identifying the amount to feed their infant $(p=.02)$. A large proportion of mothers reported no support from friends in rearing children.
\end{abstract}

Keywords: Postpartum Depression; Preterm; Mother-Infant Interaction; Parental Stress; Developing Countries

\section{Introduction}

Postpartum depression (PPD) is considered as a serious public health problem due to its enduring impact on the mental health of the mother (Hay, Pawlby, Waters, \& Sharp, 2008) and father (Goodman, 2004). In addition, it also affects family dynamics (Tammentie, Tarkka, Åstedt-Kurki, Paavilainen, \& Laippala, 2004) as well as all dimensions of child development including physical, emotional, cognitive, language, social, and attention (Black, Baqui, Zaman, Arifeen, \& Black, 2009; Grace, Evindar, \& Stewart, 2003). Recent evidence indicates that the level of PPD in low- and middle-income countries is higher than the $10 \%$ to $15 \%$ prevalence estimated for high income countries (Coast, Leone, Hirose, \& Jones, 2012). The prevalence rate of PPD worldwide ranges from $.5 \%$ to $60.8 \%$, excluding Pakistan (Halbreich \& Karkun, 2006). Amongst South Asian countries, Pakistan has the highest prevalence of PPD reported at $63.3 \%$ (Klainin \& Arthur, 2009). The question remains as to why Pakistani women have higher rates of PPD. In 2005 , worldwide statistics indicated that $9.6 \%$ of all births were preterm with Africa and Asia accounting for approximately $85 \%$ of these births. Pakistan has a preterm birth rate of $15.7 \%$ (Lone, Qureshi, \& Emmanuel, 2004). Consequently, an interrelationship may exist between preterm birth and PPD in

*Declaration of conflicting interests: We declare we have no competing interests.

Funding: The thesis work was funded by the Aga Khan University-Master of Science in Nursing Student Thesis Budget.
Pakistani women.

\section{Preterm Birth and Postpartum Depression}

Adewuya, Fatoye, Ola, Ijaodola, and Ibigbami (2005) reported that Nigerian mothers of preterm infants were 4 times more likely to develop PPD than mothers of term infants. Meta-analyses (e.g., Robertson, Grace, Wallington, \& Stewart, 2004) examining risk factors of PPD consistently relate psychosocial factors such as depression or anxiety during pregnancy, personal and family history of depression, lack of social support, and stressful life events to PPD (Vigod, Villegas, Dennis, \& Ross, 2010). None of these meta-analyses included preterm birth as a variable (Vigod et al.). Gulamani, Premji, Kanji, \& Azam (2013) indicate that culture influences mother-infant interactions and determine social support rituals thus may indirectly influence PPD. A qualitative synthesis (Vigod et al.) revealed that studies did not consistently support an increased risk of PPD in women with preterm infants. However, the authors concluded that "mothers of preterm infants are at higher risk of depression than mothers of term infants in the immediate postpartum period" (p. 540).

The Psychosocial Model of Leigh and Milgrom (2008) used to examine the interrelationship between preterm birth and PPD relates adjustment difficulty to parenting role, such as parenting stress, to PPD in a reciprocal way. Parenting stress reflects both the parent's ability to cope, based on their perception of resources available to them, and their perceptions of the child, 
including the child's characteristics and mother-infant interactions (Leigh \& Milgrom, 2008; Misri, Reebye, Milis, \& Shah, 2006). Mother-infant interaction is "the influence by the infant on the mother (infant attachment) and the influence by the mother on the infant (maternal-infant bonding) during early development" (Kashiwagi \& Shirataki, 1995: p. 246). Predisposing factors such as low income, history of depression, history of abuse, young age, and less education have negative implications for mother-infant interaction and parental stress.

In this study, we determined whether there was a significant difference in the rate of PPD between mothers of full-term infants and mothers of preterm infants residing in Karachi, Pakistan. We also examined the contribution of parenting stress and mother-infant interaction to PPD among mothers of preterm infants.

\section{Methods}

\section{Design}

Consecutive sampling was used for this cohort study to recruit a fixed number of mothers who delivered full-term infants (i.e., unexposed) and a fixed number of mothers who delivered preterm infants (i.e., exposed) that met the eligibility criteria. Although ultrasound in the first trimester is more sensitive in estimating gestational age (Kalish et al., 2004), we used last menstrual period as not all mothers had received an ultrasound in the first trimester, but last menstrual period was consistently recorded for all mothers. Preterm birth was defined as a baby being born at less than 37 weeks gestational age, and full-term birth was defined as a baby being born between 37 and 42 weeks completed gestational age. All mothers were screened for the presence of PPD at four to six weeks after delivery and completed a general questionnaire soliciting information about characteristics of the sample (e.g., age, education, income), patterns of routine life (e.g., infant feeding, work and sleep patterns) and social life (e.g., support networks, marital relationship). Mothers of preterm infants also completed the parental stress scale and the parental bonding questionnaire at this time.

\section{Sample and Procedure}

A total of 34 mothers of preterm infants and 170 mothers of full-term infants participated in the study (Figure 1) if they: 1)

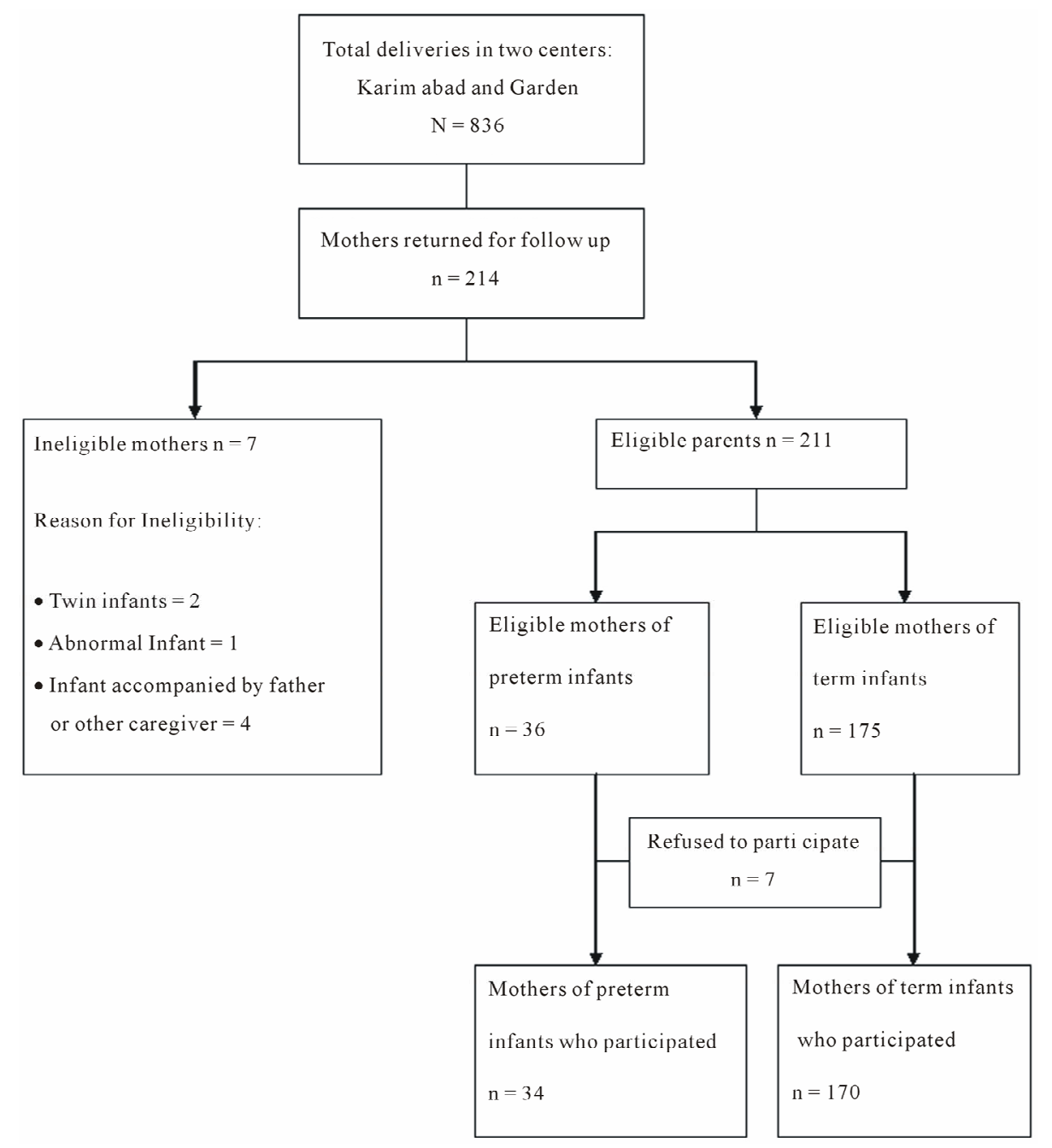

Figure 1.

Movement of mothers through the study. 
had a baby within the previous four to six weeks, 2) were between 18 to 40 years of age, 3) were able to speak Urdu or English, and 4) had not developed any complication during pregnancy (e.g. eclampsia) or after delivery (e.g. postpartum hemorrhage, sepsis). Mothers who had delivered twins or an infant with abnormalities, or had a stillbirth were not eligible for this study. A list was obtained of mothers who delivered at Aga Khan Hospital for Women and Children (AKHWC), Karimabad and Garden (Karachi, Pakistan), between May 1, 2010 to June 30, 2010. The nurse-in-charge approached mothers from this list when they returned to the postnatal clinic, infant clinic, or the vaccination room, and invited them to participate if they met the inclusion criteria.

The sample size was calculated in order to achieve a power of $80 \%$ with an anticipated relative risk of 3 , ratio of preterm and full-term mothers of $1: 5$, and level of significance of $5 \%$. We used a relative risk of 3 to ensure a conservative sample size that could be achieved during the study period. A ratio of 1:5 was maintained as the prevalence of preterm infants was very low. Furthermore, a 1:5 ratio allowed for precision in sample size so that the rate of PPD could be measured accurately (Rothman \& Greenland, 1998).

\section{Ethical Considerations}

Ethical approval for this study was obtained from the Ethical Research Committee of the Aga Khan University. The researcher or research assistant obtained informed consent prior to enrolment of women in the study.

\section{Instruments}

PPD was measured with the Edinburgh postnatal depression scale (EPDS), a ten item self-report scale that screens for the presence of symptoms of PPD (i.e., not a diagnostic instrument) (Cox, Holden, \& Sagovsky, 1987). EPDS is a reliable and valid instrument with a sensitivity of $85 \%$, and specificity of $77 \%$ (Cox et al., 1987). Extensively used in developing countries, and translated into several languages, including Urdu (Husain et al., 2006), the EPDS has been validated with a Pakistani population (Rahman, Iqbal, Lovel, \& Shah, 2005). The most common cut-off of greater-than or equal to 12 was used to indicate a positive screen for depressive illnesses.

Mother-infant interaction was measured with a 25 item parental bonding questionnaire (PBQ) based on the mother's self-report of characterization of their infant and mother-infant relationship and scored on a five-point Likert scale, with a reverse sequencing for items related to favorable aspect of the interaction (Brockington et al., 2001). The 25 items were derived from principle component analysis of 84 items, which resulted in four scales ranging in sensitivity from .93 to .28 (Brockington et al., Brockington, Fraser, \& Wilson, 2006). The PBQ has been validated with Professor Lynne Murray's Global Rating Scale (Murray \& Cooper, 1997), and by interviewing 51 mothers using an interview guide for pregnancy related disorders (Brockington et al., 2001, 2006). In a Dutch sample, the PBQ had high internal consistency for the total PBQ (Cronbach's alpha .87) when compared to the Maternal Postpartum Attachment Scale (.75) and Mother-to-Infant Bonding Scale (.67) at 8 and 12 weeks postpartum (Van Bussel, Spitz, \& Demyttenaere, 2010). Strong correlation was evident between scales of PBQ and Maternal Postpartum Attachment Scale and Mother-to-Infant Bonding (van Bussel et al., 2010). PBQ is used as a global measure of quality of mother-infant interaction, with a cut-off of 31 and above indicating clinically severe mother-infant interaction difficulties; whereas lower scores denote good bonding (Loh, 2005). The PBQ is best used with the EPDS, particularly when assessing the extent of the difficulties of the relationship between the mother and child (Klier \& Muzik, 2004). Cultural appropriateness of the Urdu version of the PBQ (back translated to ensure language equivalency) was established by piloting the instrument on 10 mothers who came to the postnatal clinic at Aga Khan University Obstetrics and Gynecology clinic. Two items, number 22 and 24, were found to be confusing for the mothers. Mothers had difficulty understanding the Urdu word used for "confident" (i.e., "yaqini kafiayat") in item 22; the word was therefore replaced with "Aitimad". In item 24, the Urdu term used for hurting (i.e., "ghira hua") was replaced with "uljha hua" for a similar reason.

The Parental Stress Scale (PSS), a self-report scale with 18 items scored on a five point scale was used to measure parental stress. The PSS has an internal reliability of .83 and test-retest reliability of .81 , and has been found to correlate with the Perceived Stress Scale $(r=.41)$ and the Parenting Stress Index $(r$ $=.75$ ) (Berry \& Jones, 1995). Higher scores on the scale are indicative of greater stress. A Chinese version of the PSS has been validated on Chinese parents (Cheung, 2000). The tool was translated into Urdu, and then back translated into English to assure quality data. As with the Urdu version of the PBQ, the Urdu version of the PSS was also pilot tested; however no changes were required.

A two-part questionnaire elicited information to develop the profile of the family: Part A focused specifically on the demographic characteristics of the mother, father, and infants; Part B assessed the medical history, feeding practice and concerns related to feeding, infant's and mother's sleep patterns, mother's social life (i.e., history of abuse of any form), and support systems, and dysfunctional relationships in the household (e.g., husband and/or mother-in-law).

\section{Data Analysis}

Data was analyzed using Statistical Packages for the Social Sciences (SPSS) version 17.0. Descriptive statistics were used to compare the characteristics of groups: mothers of full-term infants and preterm infants, full-term and preterm infants, depressed and not depressed mothers of preterm infants. Chi square or the Fisher's exact test was used for categorical data. An independent sample t test was used for continuous variable. The Mann Whitney U test was used for ordinal level data or when assumptions of independent samples t-test were violated. A Chi square test was used to determine the differences in the rate of PPD between mothers of full-term infants and mothers of preterm infants. We used logistic regression modeling to determine the odds of PPD in mothers of preterm infants compared to full-term infants. A Fisher exact test was used to determine the relationship between parental stress and PPD among mothers of preterm infants.

\section{Results}

Two hundred and fourteen (214) mothers returned to the center for follow-up care between four to six weeks after birth. Two mothers had delivered twins, one mother had an abnormal child, and four infants were accompanied by their father, aunt or grandmother and were not with their mothers, and were 
therefore excluded from the study. Two hundred and eleven (211) mothers met the inclusion criteria, but two mothers of full-term infants and five mothers of preterm infants refused to participate in the study (see Figure 1).

As can be seen in Table 1, the median gestational age of infants in the full-term group was 39 weeks, while in the preterm group it was 36 weeks, and the majority of infants in both groups were greater-than or equal to 2.5 kilograms. Also, a significantly higher representation of low birth weight infants was noted in the preterm infant group $(p=.00)$. No group differences were noted in gender, education level, ethnicity, working status, planned pregnancy, relationship difficulties with both husband and mother-in-law, domestic violence, support systems, and friends support. However, a significant difference in the mean ages of mothers was observed between the two groups $(p=.03)$. Proportionately, there were more mothers in the full-term infant group, as compared to the preterm infant group who were primiparous $(p=.03)$. Proportionately, more mothers in the preterm infant group compared to full-term infant group indicated that their infants woke up for no reason; this difference was significant $(p=.01)$.

Mothers of preterm infants showed a higher rate of PPD $(35.3 \%)$ than mothers of full-term infants $(15.3 \%)$. A Chi square test revealed a significant difference in the rate of PPD between the mothers of full-term and preterm infants $(p=.01)$. However, since significant differences were apparent in predisposing factors such as mother's age, number of children, birth weight, and infant's unexplained waking in the night univariate logistic regression analysis was undertaken. Birth status (i.e., full-term versus preterm birth) $(p<.01)$ and number of children $(p=.028)$ were significant predictors of PPD in univariate analysis (see Table 2). Mothers of preterm infants had higher odds of depression (adjusted odds ratio $=2.68,95 \%$ Confidence Interval (CI) $1.16-6.17, p=.015$ ) when compared to mothers who delivered full-term infants after controlling for number of children in the model.

As can be seen in Table 3, when the characteristics of preterm mothers are compared by depression status, there were no differences in socio-demographic, obstetric, or health history variables. No differences were found in the majority of social variables, including relationship with husband and mother-inlaw, domestic violence (physical and verbal abuse), social support from mother-in-law, social support from friends, and family type. However, proportionately, more mothers of preterm infants in the not depressed group reported that their husbands always supported them in caring for their child $(p=.03)$.

As can be seen in Table 4, there were no differences observed between the characteristics of preterm infants of depressed mothers versus those of not depressed mothers, such as gender, birth weight, and reasons for waking up in the night. Although there was no significant difference with regards to difficulty in identifying infant's hunger, mothers of preterm infants who were depressed, experienced more difficulty in feeding their infants $(p=.03)$, as well as difficulty in identifying the amount of milk to feed their infants $(p=.02)$.

The PSS data were skewed; the median was 41 for mothers of preterm infants in the depressed group, and 34 for mothers of preterm infants in the not depressed group. Since data were skewed, PSS scores above the 50th percentile were categorized as high parental stress, and scores below the 50th percentile were categorized as low parental stress. Of the 12 mothers of preterm infants who were depressed, 5 showed low parental stress and 7 showed high parental stress; whereas of the 22 mothers of preterm infants who were not depressed, 14 showed low parental stress and 7 showed high parental stress. A Fisher exact test was used to determine the relationship between parental stress and PPD among mothers of preterm infants. No significant difference was found between depressed and not depressed mothers in the proportion of mothers who showed low versus high parental stress. At $95 \% \mathrm{CI}$, there is $87.42 \%$ likelihood that there is no difference in the parental stress between depressed and not depressed mothers. Hence, the data suggest that there is no relationship between parental stress and PPD.

The PBQ data were skewed; the median was 3.5 for mothers of preterm infants in the not depressed group and 3.5 for depressed group of preterm infants. Scores on the PBQ ranged from 0 to 18 , which indicated that none of the mothers of preterm infants were found to have bonding difficulty. Given the distribution of data, no statistical test was undertaken to test the hypothesis that there is no relationship between mother-infant interaction and PPD.

\section{Discussion}

In this study, a significant difference $(p=.01)$ was found in the rate of PPD between Pakistani mothers of full-term and preterm infants: $15.3 \%$ versus $35.3 \%$, respectively. Other studies (Logsdon \& Usui, 2001; Madu \& Roos, 2006) also identified a significant difference in the rate of PPD between mothers of full-term and preterm infants. We found that mothers of preterm infants had an adjusted odds ratio of 2.68 (95\% CI 1.16 $6.17, p=.015)$ of developing PPD compared to mothers of full-term infants after controlling for group differences (e.g., number of children) through logistic regression modeling. However, significant differences were apparent in predisposing factors such as age, number of children, birth weight, and infant's unexplained waking in the night. Furthermore, infants in the preterm group were between 32 weeks and 36 weeks gestation and only of slighter lower birth weight. In two American studies (Brandon et al., 2011; Voegtline \& Stifter, 2010), care of late preterm infants has been associated with greater emotional distress, parental stress and anxiety when compared to the care of full-term infants. The high infant mortality rate associated with preterm birth and low birth weight, combined with limited community resources to support Pakistani mothers of preterm mothers in caring for their infants may also explain the high rates of PPD among mothers of preterm infants.

The findings of the current study imply that Pakistani mothers of preterm infants may be at a high risk for developing PPD. Moreover, mothers who are experiencing preterm birth for the second time have a higher chance of developing PPD (Allen, 2004). Early interventions could be planned that focus on educating mothers and fathers about the preterm infant's behavioral cues and feeding readiness, as well as nutritional requirements to promote growth and development. Using evidence to inform parents about best practices for feeding their preterm infants and providing accurate information about infants' development may increase mothers' knowledge about infant behavioral cues (Maguire, Bruil, Wit, \& Walther, 2007), and may decrease depressive symptoms (Veddovi, Kenny, Gibson, Bowen, \& Starte, 2001).

The current study found no significant difference between depressed and not depressed mothers of preterm infants in the 


\section{S. S. GULAMANI ET AL}

Table 1.

Full-term and preterm infants' characteristics and socio-demographic, obstetric and health history, and social characteristics of mothers of full-term and preterm infants.

\begin{tabular}{|c|c|c|c|}
\hline \multirow{2}{*}{ Characteristics } & \multirow{2}{*}{$\begin{array}{c}\text { Term Group } \\
\mathrm{n}=170\end{array}$} & \multirow{2}{*}{$\begin{array}{c}\text { Preterm Group } \\
\mathrm{n}=34\end{array}$} & \multirow{2}{*}{$p$ value } \\
\hline & & & \\
\hline \multicolumn{4}{|l|}{ Infants } \\
\hline \multicolumn{4}{|l|}{ Demographic } \\
\hline & Median (Range) & Median (Range) & \\
\hline \multirow[t]{2}{*}{ Gestational Age (in Weeks) } & 39 (37 to 42$)$ & $36(32$ to 36$)$ & \\
\hline & $\mathrm{n}(\%)$ & $\mathrm{n}(\%)$ & \\
\hline Weight & & & ${ }^{*} 0.00^{\dagger}$ \\
\hline$<2.5 \mathrm{Kg}$ & $15(9)$ & $12(35)$ & \\
\hline$>2.5 \mathrm{Kg}$ & $152(91)$ & $22(65)$ & \\
\hline Gender & & & $0.61 \sim$ \\
\hline Baby Boy & $73(42.9)$ & $13(38.2)$ & \\
\hline Baby Girl & $97(57.1)$ & $21(61.8)$ & \\
\hline \multicolumn{4}{|l|}{ Behavior } \\
\hline Reason for Waking up in the Night & & & $0.01^{* \dagger}$ \\
\hline Hungry & $153(90)$ & $24(70.6)$ & \\
\hline No Reason & $6(3.5)$ & $5(14.7)$ & \\
\hline Does Not Wakeup & $8(4.7)$ & $2(5.9)$ & \\
\hline Others & $3(1.8)$ & $3(8.8)$ & \\
\hline \multicolumn{4}{|l|}{ Mothers } \\
\hline \multicolumn{4}{|l|}{ Socio-Demographic } \\
\hline \multirow{3}{*}{ Age } & Mean (SD) & Mean (SD) & \\
\hline & $26.02(4.09)$ & $27.67(3.81)$ & $0.03^{*} \wedge$ \\
\hline & $\mathrm{n}(\%)$ & $\mathrm{n}(\%)$ & \\
\hline Education Level & & & $0.95 \sim$ \\
\hline Graduate and Above & $99(58.2)$ & $20(58.8)$ & \\
\hline Others & $71(41.8)$ & $14(41.2)$ & \\
\hline Ethnicity & & & $0.90 \sim$ \\
\hline Muhajir & $93(54.7)$ & $19(55.9)$ & \\
\hline Others & $77(45.3)$ & $15(44.1)$ & \\
\hline Working Status & & & $0.72^{\dagger}$ \\
\hline Yes & $12(7.1)$ & $3(8.8)$ & \\
\hline No & $158(92.9)$ & $31(91.2)$ & \\
\hline \multicolumn{4}{|l|}{ Obstetric \& Health History } \\
\hline Number of Children & & & $0.03^{*} \alpha$ \\
\hline One & $86(50.6)$ & $11(32.4)$ & \\
\hline Two & $52(30.6)$ & $12(35.2)$ & \\
\hline Three and More & $32(18.8)$ & $11(32.4)$ & \\
\hline Planned Pregnancy & & & $0.84 \sim$ \\
\hline Yes & $117(68.8)$ & $24(70.6)$ & \\
\hline No & $53(31.2)$ & $10(29.4)$ & \\
\hline Past Psychiatric Illness & & & NA \\
\hline Yes & $3(1.8)$ & 0 & \\
\hline No & $167(98.2)$ & $34(100)$ & \\
\hline \multicolumn{4}{|l|}{ Social } \\
\hline \multicolumn{4}{|l|}{ Relationship Difficulties } \\
\hline With Husband & & & $0.19^{\dagger}$ \\
\hline Yes & $3(1.8)$ & $2(5.9)$ & \\
\hline No & $167(98.2)$ & $32(94.1)$ & \\
\hline With Mother-in-Law & & & $0.41^{\dagger}$ \\
\hline Yes & $2(1.2)$ & $1(3.1)$ & \\
\hline No & $168(98.8)$ & $31(96.9)$ & \\
\hline \multicolumn{4}{|l|}{ Domestic Violence } \\
\hline Punched, Kicked or Hit & & & $>0.99^{\dagger}$ \\
\hline
\end{tabular}




\begin{tabular}{|c|c|c|c|}
\hline Never & $166(97.6)$ & $33(97.1)$ & \\
\hline Sometimes to Always & $4(2.4)$ & $1(2.9)$ & \\
\hline Bad language & & & $>0.99^{\dagger}$ \\
\hline Never & $166(97.6)$ & $33(97.1)$ & \\
\hline Sometimes to Always & $4(2.4)$ & $1(2.9)$ & \\
\hline \multicolumn{4}{|l|}{ Support System } \\
\hline Husband Support & & & $0.24 \alpha$ \\
\hline Never & $5(2.9)$ & $1(2.9)$ & \\
\hline Sometimes & $22(12.9)$ & $7(20.6)$ & \\
\hline Often & $21(12.4)$ & $5(14.7)$ & \\
\hline Always & $122(71.8)$ & $21(61.8)$ & \\
\hline Mother-In-Law & & & $0.37 \alpha$ \\
\hline Never & $41(24.1)$ & $7(20.6)$ & \\
\hline Sometimes & $7(4.1)$ & $3(8.8)$ & \\
\hline Often & $15(8.8)$ & $7(20.6)$ & \\
\hline Always & $107(63)$ & $17(50)$ & \\
\hline Friends Support & & & $0.20 \alpha$ \\
\hline Never & $144(84.7)$ & $26(76.5)$ & \\
\hline Sometimes & $6(3.5)$ & $1(2.9)$ & \\
\hline Often & $6(3.5)$ & $1(2.9)$ & \\
\hline Always & $14(8.2)$ & $6(17.6)$ & \\
\hline
\end{tabular}

$\mathrm{SD}=$ Standard deviation; NA $=$ not applicable; $>=$ greater than. ${ }^{*}$ Significant $p$ value. ${ }^{\wedge}$ Independent samples t Test. $\sim$ : Pearson chi square. ${ }^{\dagger}$ Fishers Exact Test. $\alpha$ : Mann Whitney U Test.

Table 2.

Univariate logistic regression analysis.

\begin{tabular}{cccc}
\hline Characteristics & $\begin{array}{c}\text { Odds } \\
\text { Ratio }\end{array}$ & $\begin{array}{c}95 \% \text { Confidence } \\
\text { Interval }\end{array}$ & $p$ Value \\
\hline $\begin{array}{c}\text { Mother's Age } \\
\text { (in Years) }\end{array}$ & 1.032 & $0.95-1.12$ & 0.475 \\
$\begin{array}{c}\text { Reason for Night } \\
\text { Waking }\end{array}$ & 0.91 & $0.19-4.48$ & 0.909 \\
Birth Weight & 1.43 & $0.53-3.85$ & 0.481 \\
$\begin{array}{c}\text { Birth Status } \\
\text { (Term/Preterm) }\end{array}$ & 3.02 & $1.33-6.85$ & $0.008^{*}$ \\
Children & & & \\
1 & 1.00 & & \\
2 & 2.74 & $1.12-6.74$ & $0.028^{*}$ \\
3 & 1.98 & $0.85-4.62$ & 0.113 \\
\hline
\end{tabular}

"Significant $p$ value.

proportion of mothers who showed low versus high parental stress. Studies (Davis, Edwards, Mohay, \& Wollin, 2003; Olafsen et al., 2008) have reported higher levels of parental stress in mothers of preterm infants. However, these studies did not compare parental stress between mothers of preterm infants who were depressed versus those who were not depressed. Additionally, methodological heterogeneity exists between these studies and the current study. For instance, the current study used a parental stress scale to measure stress, whereas other studies used the parental stress index (Olafsen et al.) or the depression anxiety stress scale (Davis et al., 2003). In the current study, mothers were recruited from outpatient clinics while other studies recruited mothers of infants in the neonatal intensive care unit (Davis et al., 2003), or post hospital discharge (Olafsen et al.).

Understanding the mothers' experience of having a preterm infant becomes important to provide context to this finding of no significant difference in parental stress in mothers of preterm mothers who were depressed compared to those who were not depressed. In the current study, mothers of preterm infants also did not experience any bonding difficulty. One possible explanation for the finding may be that Pakistani mothers are not sufficiently engaged with their infants, as the primary care giver is usually the mother-in-law or other family elder. Alternately, Feeley, Gottlieb, and Zelkowitz (2005) have indicated that mothers with a higher education level show more sensitive responses towards their preterm infants. A majority of mothers who delivered preterm infants were baccalaureate or graduate prepared, therefore, the mothers may have been able to interact effectively and establish good bonding with their preterm infants; hence did not experience parental stress.

The lack of mother-infant bonding difficulties may also be related to the performance of the tool, as the psychometric properties of the Urdu version of the PBQ have not been examined. A German study was unable to confirm the original 4 factor structure when testing the psychometric properties of the German version of the PBQ (Reck et al., 2006). Reck et al.'s findings suggest that one general factor, that is impaired bonding, explained $23.9 \%$ of the total variance; the internal consistency being .85. Additionally, a 16-item version of the PBQ was proposed, as 9 items had no meaningful loading on impaired bonding. In Reck et al.'s study the EPDS score was correlated with the PBQ score $(r=.43, p<.001)$. Furthermore, $15 \%$ of variance in the scores was shown to be related to the joint variance of the two instruments (Reck et al.). The lower rates of bonding impairment in their study, when compared to Brockington et al. (2001), were attributed to differences in sample (Reck et al.). Similar to Reck et al. we recruited a community sample.

In our study, depressed mothers of preterm infants reported receiving significantly less support from their husbands. The 


\section{S. S. GULAMANI ET AL.}

Table 3.

Characteristics or preterm mothers by depression status.

\begin{tabular}{|c|c|c|c|}
\hline \multirow{3}{*}{ Characteristic } & \multicolumn{2}{|c|}{ Depression Status } & \multirow{3}{*}{$p$ Value } \\
\hline & Depressed & Not Depressed & \\
\hline & $\mathrm{n}=12$ & $\mathrm{n}=22$ & \\
\hline \multicolumn{4}{|l|}{ Socio-Demographic } \\
\hline & Median (Range) & Median (Range) & \\
\hline \multirow[t]{2}{*}{ Mothers' Age } & $27(13)$ & $27(14)$ & $0.72^{\wedge}$ \\
\hline & $\mathrm{n}$ & $\mathrm{n}$ & \\
\hline Mothers' Education & & & $>0.99^{\dagger}$ \\
\hline Graduate and Above & 7 & 13 & \\
\hline Others & 5 & 9 & \\
\hline Mothers' Ethnicity & & & $0.83 \sim$ \\
\hline Muhajir & 7 & 12 & \\
\hline Others & 5 & 10 & \\
\hline Mothers' Working Status & & & $>0.99^{\dagger}$ \\
\hline Yes & 1 & 2 & \\
\hline No & 11 & 20 & \\
\hline \multicolumn{4}{|l|}{ Obstetric \& Health History } \\
\hline Number of Children & & & $0.66 \alpha$ \\
\hline One & 4 & 7 & \\
\hline Two & 5 & 7 & \\
\hline Three and More & 3 & 8 & \\
\hline Planned Pregnancy & & & $0.27^{\dagger}$ \\
\hline Yes & 7 & 17 & \\
\hline No & 5 & 5 & \\
\hline Past Psychiatric Illness & & & NA \\
\hline Yes & 0 & 0 & \\
\hline No & 12 & 22 & \\
\hline \multicolumn{4}{|l|}{ Social } \\
\hline \multicolumn{4}{|l|}{ Relationship Difficulties } \\
\hline With Husband & & & $0.12^{\dagger}$ \\
\hline Yes & 2 & 0 & \\
\hline No & 10 & 22 & \\
\hline With Mother-In-Law & & & $0.33^{\dagger}$ \\
\hline Yes & 2 & 0 & \\
\hline No & 10 & 22 & \\
\hline \multicolumn{4}{|l|}{ Domestic Violence } \\
\hline Punched, Kicked, or Hit & & & $0.35^{\dagger}$ \\
\hline Never & 11 & 22 & \\
\hline Sometimes & 1 & 0 & \\
\hline Bad Language & & & $0.35^{\dagger}$ \\
\hline Never & 11 & 22 & \\
\hline Sometimes & 1 & 0 & \\
\hline \multicolumn{4}{|l|}{ Support System } \\
\hline Husband Support & & & $0.03^{*} \wedge$ \\
\hline Never & 1 & 0 & \\
\hline Sometimes & 5 & 2 & \\
\hline Often & 1 & 4 & \\
\hline Always & 5 & 16 & \\
\hline Mother-in-Law & & & $0.13^{\wedge}$ \\
\hline Never & 3 & 4 & \\
\hline Sometimes & 3 & 0 & \\
\hline Often & 2 & 5 & \\
\hline Always & 4 & 13 & \\
\hline Friends' Support & & & $0.90^{\wedge}$ \\
\hline Never & 9 & 17 & \\
\hline Sometimes & 0 & 1 & \\
\hline Often & 1 & 0 & \\
\hline Always & 2 & 4 & \\
\hline Family Type & & & $>0.99^{\dagger}$ \\
\hline Nuclear & 3 & 5 & \\
\hline Extended & 9 & 17 & \\
\hline
\end{tabular}

$>=$ greater than. ${ }^{\wedge}$ Mann Whitney U Test. ${ }^{\dagger}$ Fishers Exact Test. $\sim$ : Pearson chi square. ${ }^{*}$ Significant $p$ value. 


\section{S. S. GULAMANI ET AL}

Table 4.

Distribution of infants' characteristics of preterm infants group by depression status.

\begin{tabular}{|c|c|c|c|}
\hline \multirow{4}{*}{ Characteristics } & \multicolumn{2}{|c|}{ Depression Status } & \multirow{4}{*}{$p$ value } \\
\hline & Depressed & \multirow{2}{*}{$\begin{array}{c}\text { Not Depressed } \\
\mathrm{n}=22\end{array}$} & \\
\hline & $\mathrm{n}=12$ & & \\
\hline & $\mathrm{n}$ & $\mathrm{n}$ & \\
\hline Gender & & & $0.73^{\dagger}$ \\
\hline Baby Boy & 4 & 9 & \\
\hline Baby Girl & 8 & 13 & \\
\hline Birth Weight & & & $0.27^{\dagger}$ \\
\hline$<2.5 \mathrm{Kg}$ & 6 & 6 & \\
\hline $2.5 \mathrm{Kg}$ and Above & 6 & 16 & \\
\hline Reasons for Waking up in the & & & $0.08^{\dagger}$ \\
\hline Hungry & 8 & 16 & \\
\hline No Reason & 4 & 3 & \\
\hline Does Not Wakeup & 0 & 1 & \\
\hline Others & 0 & 2 & \\
\hline \multicolumn{4}{|l|}{ Feeding Practices } \\
\hline Difficulty in Feeding Infants & & & ${ }^{*} 0.03 \alpha$ \\
\hline Never & 6 & 19 & \\
\hline Sometimes & 4 & 2 & \\
\hline Often & 2 & 1 & \\
\hline \multicolumn{2}{|c|}{ Difficulty in Identifying Infants' Hunger } & & $0.08 \alpha$ \\
\hline Never & 7 & 19 & \\
\hline Sometimes & 4 & 2 & \\
\hline Often & 1 & 1 & \\
\hline \multicolumn{2}{|c|}{ Difficulty in Identifying the Amount to Feed Infants } & & ${ }^{*} 0.02 \alpha$ \\
\hline Never & 6 & 19 & \\
\hline Sometimes & 4 & 3 & \\
\hline Often & 2 & 0 & \\
\hline
\end{tabular}

$\mathrm{Kg}=$ Kilogram. ${ }^{\dagger}$ Fishers Exact Test. $\alpha$ : Mann Whitney U Test. " Significant $p$ value.

importance the mother attached to the source of support and the level of support apparent to her from this source, altered her appraisal of the stressful situation (Logsdon \& Usui, 2001). In instances when a woman attaches more importance to support from a specific source (such as her husband), and does not feel she has received that support, the incidence of PPD is higher. Furthermore, typical support systems will not meet her needs (Logsdon \& Usui, 2001). Hence, although involving the father may be difficult in a male dominated society, which is characteristic of Pakistan, attempts should be made to include them.

Regardless of depression status, mothers of preterm infants indicated that they never utilized the support of friends. Veddovi et al. (2001) found that mothers who mingled in social gatherings showed less depressive symptoms. Hence, social networking (in person and online) could support Pakistani mothers of preterm infants by assisting them to manage the challenges they are experiencing in caring for their preterm infant. A buddy program, whereby mothers of preterm infants support other mothers of preterm infants by sharing experiences and helping to identify effective coping strategies, has been shown to decrease depressive symptoms in mothers of preterm infants (Preyde \& Ardal, 2003). The AKHWC: Garden and Karimabad could implement such a social networking strategy or buddy program and evaluate its effectiveness.

The limitation of this study is that only those mothers who returned to centers for follow-up care (i.e., postpartum or infant care) were approached to participate in the study. They represent only $25.6 \%$ of mothers who delivered in the two centers. This rate of postpartum care is lower than the reported rate of $40 \%$ in low- and middle-income countries (Matthews, Severin, \& Jelka, 2010). Furthermore, we did not measure all risk factors for depression, for instance depression and anxiety during pregnancy, and life events. Although we examined previous history of depression and social support, this was through maternal self-report which is subject to bias. Given the wide confidence intervals in the adjusted odds ratio (95\% CI 1.16 - 6.17) these confounder may be distributed differently between the groups.

Samples were recruited from two hospitals run by a private organization, and were found to be homogenous in terms of economic and educational background, as evident from the demographic characteristics of the participants. One of the drawbacks of using a homogenous sample is that the external validity of the study is limited. The findings of this study may not be applied to other settings such as government institutions, where the income and education level of the mothers is significantly different. In addition, the instruments used to measure parenting stress and mother-infant interaction were not adequately tested for their validity and reliability in the Pakistani population. Lastly, given the small number of preterm infants, our study did not have sufficient statistical power to make inferences regarding the potential contribution of parenting stress 
to PPD among mothers of preterm infants.

The study findings suggest that Pakistani mothers of preterm infants are at a higher risk for PPD as compared to mothers of full-term infants who sought the services of the AKHWC, Karachi, Pakistan. Feeding challenges and the level of support available to mothers of preterm infants who were depressed versus those who were not depressed may partially explain the findings. However, PPD in mothers caring for preterm infants could not be explained with respect to parenting stress and mother-infant interaction difficulties. Nurses need to be aware that the preterm birth has the potential of increasing the risk of PPD, and could plan care in ways that enhances maternal confidence and competence for feeding preterm infants. As well, nurses could promote involvement of the father in the care of the preterm infant.

\section{Acknowledgements}

We wish to thank Dr. Tak Fung and M. Sarah Rose for their support with the advanced statistical analysis and Jennifer Carkner for providing technical assistance in the finalization of the paper. We wish to thank the Pakistani women for participating in the study. The thesis was awarded the Sigma Theta Tau International Chapter Research Award, 2010.

\section{REFERENCES}

Adewuya, A. O., Fatoye, F. O., Ola, B. A., Ijaodola, O. R., \& Ibigbami, S. O. (2005). Sociodemographic and obstetric risk factors for postpartum depression symptoms in Nigerian women. Journal of Psychiatric Practice, 11, 63-70. http://dx.doi.org/10.1097/00131746-200509000-00009

Allen, E. C., Manuel, J. C., Legault, C., Naughton, M. J., Pivor, C., \& O'Shea, T. M. (2004). Perception of child vulnerability among mothers of former premature infants. Pediatrics, 113, 267-273. http://dx.doi.org/10.1542/peds.113.2.267

Black, M. M., Baqui, A. H., Zaman, K., Arifeen, S. E. I., \& Black, R. E. (2009). Maternal depressive symptoms and infant growth in rural Bangladesh. American Journal of Clinical Nutrition, 89, 951-957. http://dx.doi.org/10.3945/ajcn.2008.26692E

Berry, J. O., \& Jones, W. H. (1995). The parental stress scale: Initial psychometric evidence. Journal of Social and Personal Relationships, 12, 463-472. http://dx.doi.org/10.1177/0265407595123009

Brandon, D. H., Tully, K. P., Silva, S. G., Malcolm, W. F., Murtha, A. P., Turner, B. S., \& Holditch-Davis, D. (2011). Emotional responses of mothers of late-preterm and term infants. Journal of Obstetric, Gynecologic, \& Neonatal Nursing, 40, 719-731. http://dx.doi.org/10.1111/j.1552-6909.2011.01290.x

Brockington, I. F., Fraser, C., \& Wilson, D. (2006). The postpartum bonding questionnaire: A validation. Archives of Women's Mental Health, 9, 233-242. http://dx.doi.org/10.1007/s00737-006-0132-1

Brockington, I. F., Oates, J., George, S., Turner, D., Vostanis, P., Sullivan, M., Loh, C., \& Murdoch, C. (2001). A screening questionnaire for mother-infant bonding disorders. Archives of Women's Mental Health, 3, 133-140. http://dx.doi.org/10.1007/s007370170010

Cheung, S. K. (2000). Psychometric properties of the Chinese version of the parental stress scale. Pscyhologia, 43, 253-261.

Coast, E., Leone, T., Hirose, A., \& Jones, E. (2012). Poverty and postnatal depression: A systematic mapping of the evidence from low and lower middle income countries. Health Place, 18, 1188-1197. http://dx.doi.org/10.1016/j.healthplace.2012.05.004

Cox, J. L., Holden, J. M., \& Sagovsky, R. (1987). Detection of postnatal depression: Development of the 10-item Edinburgh postnatal depression scale. British Journal of Psychiatry, 150, 782-786. http://dx.doi.org/10.1192/bjp.150.6.782

Davis, L., Edwards, H., Mohay, H., \& Wollin, J. (2003). The impact of very premature birth on the psychological health of mothers. Early
Human Development, 73, 61-70.

http://dx.doi.org/10.1016/S0378-3782(03)00073-2

Feeley, N., Gottlieb, L., \& Zelkowitz, P. (2005). Infant, mother and contextual predictors of mother-very low birth weight infant interaction at 9 months of age. Journal of Developmental \& Behavioral Pediatrics, 26, 24-33.

Goodman, J. H. (2004). Paternal postpartum depression, its relationship to maternal postpartum depression, and implications for family health. Journal of Advanced Nursing, 45, 26-35. http://dx.doi.org/10.1046/j.1365-2648.2003.02857.x

Grace, S. L., Evindar, A., \& Stewart, D. E. (2003). The effect of postpartum depression on child cognitive development and behavior: A review and critical analysis of the literature. Archives of Women's Mental Health, 6, 263-274.

http://dx.doi.org/10.1007/s00737-003-0024-6

Gulamani, S. S., Premji, S. S., Kanji, Z. K., \& Azam, S. I. (2013). A review of postpartumdepression, preterm birth and culture. Journal of Perinatal and Neonatal Nursing, 27, 52-61. http://dx.doi.org/10.1097/JPN.0b013e31827fcf24

Halbreich, U., \& Karkun, S. (2006). Cross cultural and social diversity of prevalence of postpartum depression and depressive symptoms. Journal of Affective Disorder, 91, 97-111. http://dx.doi.org/10.1016/j.jad.2005.12.051

Hay, D. F., Pawlby, S., Waters, C. D., \& Sharp, D. (2008). Antepartum and postpartum exposure to maternal depression: Different effects on different adolescent outcomes. Journal of Child Psychology and Psychiatry, 49, 1079-1088. http://dx.doi.org/10.1111/j.1469-7610.2008.01959.x

Husain, N., Beve, I., Husain, M., Chaudhry, I. B., Atif, N., \& Rahman, A. (2006). Prevalence and social correlates of postnatal depression in a low income country. Archives of Women's Mental Health, 9, 197-202. http://dx.doi.org/10.1007/s00737-006-0129-9

Kalish, R. B., Thaler, H. T., Chasen, S. T., Gupta, M., Berman, S. J., Rosenwaks, Z., \& Chervenak, F. A. (2004). First- and second-trimester ultrasound assessment of gestational age. American Journal of Obstetrics \& Gynecology, 191, 975-978. http://dx.doi.org/10.1016/j.ajog.2004.06.053

Kashiwagi, H., \& Shirataki, S. (1995). Development in mother infant en face interaction of high risk newborn infants: A longitudinal follow up from 0 to 7 months. Early Human Development, 43, 245-270. http://dx.doi.org/10.1016/0378-3782(95)01685-6

Klainin, P., \& Arthur, D. G. (2009). Postpartum depression in Asian cultures: A literature review. International Journal of Nursing Studies, 2, 1-19.

Klier, C. M., \& Muzik, M. (2004). Mother-infant bonding disorders and use of parental bonding questionnaire in clinical practice. World Psychiatry, 3, 102-103.

Leigh, B., \& Milgrom J. (2008). Risk factors for antenatal depression, postnatal depression and parenting stress. BMC Psychiatry, 75, 2329.

Logsdon, M. C., \& Usui, W. (2001). Psychosocial predictors of postpartum depression in diverse groups of women. Western Journal of Nursing Research, 23, 563-574.

Loh, C. C. (2005). Assessment of mother-infant relationship difficulties in postpartum depression. Doctoral Dissertation, Kuala Lumpur: University of Malaysia (UKM).

Lone, F. W., Qureshi, R. N., \& Emmanuel, F. (2004). Maternal anemia and its impact on perinatal outcome in a tertiary care hospital in Pakistan. Eastern Mediterranean Health Journal, 10, 801-807.

Madu, S. N., \& Roos, J. J. (2006). Depression among mothers with preterm infants and their stress coping strategies. Social Behavior and Personality, 34, 877-890. http://dx.doi.org/10.2224/sbp.2006.34.7.877

Maguire, C. M., Bruil, J., Wit, J. M., \& Walther, F. J. (2007). Reading preterm infant's behavioral cues: An intervention study with parents of premature infants born $<32$ weeks. Early Human Development, 83, 419-424. http://dx.doi.org/10.1016/j.earlhumdev.2007.03.004

Matthews, M., Severin, V. X., \& Jelka, Z. (2010). WHO technical consultation on postpartum and postnatal care. Geneva: World Health Organization.

Misri, S., Reebye, P., Milis, L., \& Shah, S. (2006). The impact of 


\section{S. S. GULAMANI ET AL.}

treatment intervention on parenting stress in postpartum depressed mothers: A prospective study. American Journal of Orthopsychiatry, 76, 115-119. http://dx.doi.org/10.1037/0002-9432.76.1.115

Murray, L., \& Cooper, P. J. (1997). The role of infant and maternal factors in postpartum depression, mother-infant interaction and infant outcome. In L. Murray, \& P. J. Cooper (Eds.), Postpartum depression and child developments (pp. 111-135). New York: Guildford Press.

Olafsen, K. S., Kaaresen, P. I., Handegard, B. H., Ulvund, S. E., Dahl, L. B., \& Ronning, J. A. (2008). Maternal ratings of infant regulatory competence from 6 to 12 months: Influence of perceived stress, birth weight and intervention a randomized control trial. Infant Behavior and Development, 31, 408-421.

http://dx.doi.org/10.1016/j.infbeh.2007.12.005

Preyde, M., \& Ardal, F. (2003). Effectiveness of a parent buddy program for mothers of very preterm infants in a neonatal intensive care unit. Canadian Medical Association Journal, 168, 969-973.

Rahman, A., Iqbal, Z., Lovel, H., \& Shah M. A. (2005). Screening for postnatal depression in the developing world: A comparison of the WHO self-reporting questionnaire (SRQ-20) and the Edinburgh postnatal depression screen (EPDS). Journal of Pakistan Psychiatric Society, 2, 69-72.

Reck, C., Klier, C. M., Pabst, K., Stehle, E., Steffenelli, U., Struben, K., \& Backenstrass, M. (2006). The German version of the postpartum bonding instrument: Psychometric properties and association with postpartum depression. Archives of Women's Mental Health, 9, 265-271. http://dx.doi.org/10.1007/s00737-006-0144-x

Robertson, E., Grace, S., Wallington, T., \& Stewart, D. E. (2004). An- tenatal risk factors for postpartum depression: A synthesis of recent literature. General Hospital Psychiatry, 26, 289-295.

http://dx.doi.org/10.1016/j.genhosppsych.2004.02.006

Rothma, K. J., \& Greenland, S. (1998). Modern epidemiology (2nd ed.). Philadelphia: Lippincott-Raven Publishers.

Tammentie, T., Tarkka, M.-T., Åstedt-Kurki, P., Paavilainen, E., \& Laippala, P. (2004). Family dynamics and postnatal depression. Journal of Psychiatric Mental Health Nursing, 11, 141-149. http://dx.doi.org/10.1111/j.1365-2850.2003.00684.x

Van Bussel, J. C. H., Spitz, B., \& Demyttenaere, K. (2010). Three self-report questionnaires of the early mother-to-infant bond: Reliability and validity of the Dutch version of the MPAS, PBQ and MIBS. Archives of Women's Mental Health, 13, 373-384.

Veddovi, M., Kenny, D. T., Gibson, F., Bowen, J., \& Starte, D. (2001). The relationship between depressive symptoms following premature birth, mothers' coping style and knowledge of infant development. Journal of Reproductive Infant and Psychology, 19, 313-323.

Vigod, S. N., Villegas, L., Dennis, C. L., \& Ross, L. E. (2010) Prevalence and risk factors for postpartum depression among women with preterm and low-birth-weight infants: A systemic review. BJOG, 117, 540-550.

Voegtline, K. M., \& Stifter, C. A. (2010). Family life project investigators. Late-preterm birth, maternal symptomatology, and infant negativity. Infant Behavior and Development, 33, 545-554. 